\title{
PHANTASMATA OF DANCE: TIME AND MEMORY WITHIN CHOREOGRAPHIC CONSTRAINTS
}

\author{
SILVIA CASINI
}

\begin{abstract}
This article contributes to the scholarly discussion of the relationship between cinema and dance using Giorgio Agamben's understanding of dance as gesture. To render Agamben's critical framework operative, however, one needs to consider his reference to the concept of phantasmata (images) taken from Domenico da Piacenza's Renaissance treatise on choreography. Agamben returns to this treatise to support his argument that dance is concerned first and foremost with time and memory rather than space and the present. To notate dance as a sequence of moving images is not simply to make visible on screen a series of bodily movements in space. Rather, it means acknowledging that dancing is primarily a mental activity. Taking Agamben's reflections on dance and using Maya Deren's work on screen dance as a case-study, this article discusses how cinema and dance together prompt us to undo the economy of bodily movements, restoring the body to us transfigured.
\end{abstract}

Keywords: Agamben; Maya Deren; phantasmata; inoperative; potentiality; memory; Domenico da Piacenza; gesture

\section{Introduction}

A fascination with the spectacle of the body in movement links cinema and dance, despite the very different relations of each, in phenomenological terms, to time and space. Dance exists, first, as a performance happening in real time and space. Cinema, by contrast, manipulates its own time and space:

Cinema is, of course, simultaneously, an art of space and of time. A moving body occupies space, yet these spaces are not fixed moments but acts of duration, or space-in-time, recorded and projected in the classic celluloid format at a speed of twenty-four frames per second. The moving body thus succeeds in 'being' (spatial) and 'becoming' (temporal) by expressing duration, with time and space collapsing together to form a moving present. ${ }^{1}$

The moving body in cinema is a presence and a becoming; it is present here and now, and it becomes there and then. The encounter between dance and cinema, two arts of organizing bodies in space and time, produces intriguing results that transgress both art forms. In the early days of 
cinema, the attempt to break down the movement of bodies and to capture the various phases of movement in space and time was seen in Eadweard Muybridge's photographic sequences as well as in Etienne-Jules Marey's chronophotographic studies. ${ }^{2}$ Cinema did not limit itself to the study of movement as an abstract category: for example, both Méliès and Lumière used actual dancers in The Magic Lantern (1903) and Fire Dance (1906) - the latter starring the dancer Loïe Fuller.

If the collaboration between dance and cinema seems straightforward in musicals and classic Hollywood films - for example, Seven Brides for Seven Brothers (1954), one of the first dance films in wide-screen format - this is not true of all cinema/dance overlap. Since the 1920s, a variety of experiments with dance have been conducted across the different avant-garde movements in cinema and the arts. Prominent examples are Fernand Léger's Ballet mécanique (1924), a landmark experiment with camera-created motion and rhythm; Germaine Dulac's Thèmes et variations (1928), which compares and contrasts the gestures of the dancer with the mechanised movements of the machine; Maya Deren's dance-based films (discussed in more detail below); the films by Ruttmann, Len-Lye and Fischinger posing a "structural analogy" between cinema and dance in terms of the play of forms, light and movements beyond any narrative constraints; and more recently, William Klein's Babilée '91 (1992 with its focus on the way in which the body moves and transforms the space around it during rehearsals.

Even a cursory review of the history of the relationship between dance and cinema reveals that dance film has become a recognized subgenre across avant-garde art and popular culture, relating time, space and movement across a variety of media (the body, celluloid film, video etc.). Although the intersection of dance, film, video and new media has been explored across genres, epochs and cultural traditions, the contribution of dance theory to cinema remains relatively undertheorized, as Brannigan points out:

[W] hile dance studies has often kept its distance from debates in film theory, film has also avoided dialogue with issues in dance studies [...]. Dance theory offers understandings of the moving body and its ability to produce and express meanings that are particularly useful for addressing both popular film genres and other categories of dancefilm. ${ }^{3}$

The relationship between cinema and dance is, therefore, more nuanced than it would seem at first glance. Since the twentieth-century avant-garde revolution embodied by dancers such as Delsarte, Duncan, Laban, Graham, Cunningham and Bausch, dance has ceased to be merely a divertissement. It has become a self-reflexive art that interrogates its own methods, its position within cultural history, and functions as a means for better grasping our condition as human beings. ${ }^{4}$ 
From this revolution, and thanks to a productive exchange with key theories that called for a re-thinking of corporeality, dance has come to be recognized as a way of thinking through the relationship between the body and the world, opening up the possibility to transcend both in the act of dancing. ${ }^{5}$ Transcendence does not mean escapism, but rather inhabiting the forms and movements of the dancer, a type of experience that is contingent and charged with time: in a choreographic sequence, every dancing gesture and movement is brought to its completion until it transforms itself into either a pause (stillness) or the next movement. Dance, as Badiou argues following Nietzsche, is a mental activity, for it shows what the body is capable of beyond any physical constraints, the body unleashed from its embodiment:

It should be noted that dance, which is both bird and flight, is also everything that the infant designates. Dance is innocence, because it is a body before the body. It is forgetting, because it is a body that forgets its fetters, its weight. It is a new beginning, because the dancing gesture must always be something like the invention of its own beginning. And it is also play, of course, because dance frees the body from all social mimicry, from all gravity and conformity. A wheel that turns itself. [...] [T] he essence of dance is virtual rather than actual movement; [...] dance is composed of gestures that, haunted by their own restraint, remain in some sense undecided. ${ }^{6}$

In this passage, dance is both material (a body) and abstract (innocence, an image). It is animal and human, real movement and thought; it is action and endurance, a body before the body, a body in all its potential.

More than any other scholarly dance critics, it is Agamben, in his reflections on dance as gesture, who offers a critical lens through which the relationship between dance and cinema can [best?] be re-assessed. ${ }^{7}$ If Badiou had the merit of theorizing dance as a mental rather than a physical activity, Agamben pushes Badiou's reflections further by discussing choreography as both a restraint and a possibility for the body, and not just as the articulation of a series of movements. ${ }^{8}$ Agamben argues that dance gives cinema the opportunity to explore the status of the moving image - that is, the theme of forms and their becoming.

This article contributes to the scholarly discussion of the relationship between cinema and dance by using Agamben's understanding of dance as gesture. To render operative Agamben's critical framework, however, we need to take into account his reference to the concept of phantasmata (images) taken from Domenico da Piacenza's Renaissance treatise on choreography. Agamben returns to this treatise to support his argument that dance is concerned primarily with time and memory, rather than space and the present. Cinema becomes a form of dance notation (a choreography), but in images rather than in symbols or words. To notate dance as a sequence of 
moving images is not simply to record and make visible on screen a series of bodily movements in space. Rather, it acknowledges that dancing itself is first a mental activity, a form of thinking that can take place, paradoxically, even in the absence of a moving body. This is not to say that dancing occurs literally without a body but, rather, that the act of dancing is not simply connected to the corporeality of an individual body. Dancing is an act of rebellion aimed at unmasking any choreographic ritual and protocols, not just for the dancer but also for the spectators' collective body.

By taking Agamben's reflections on dance and using Maya Deren's work on screen dance as a case-study, this article discusses how cinema and dance together prompt us to undo the economy of bodily movements. The article argues that this undoing occurs thanks to the interplay between stasis and movement, two crucial phases of every dance, which are illustrated by two images (phantasmata) in da Piacenza's treatise: arrest/interruption (the Medusa's head) and movement/action (the falcon). For Agamben, to dance is not simply to perform a series of bodily movements in space, but also to move through temporal layers and spectral images thanks to memory. Just as Agamben conceives of cinema outside the image - the concept of cinema as gesture rather than image-based - he also conceives of dance outside movement. Dance shows the possibility of movement without a destination. This radical attempt to disentangle dance from bodies moving in space enables us to conceive of dance as a type of life form in which the condition of being unproductive becomes activated.

To illustrate the relationship and exchange between dance and cinema as characterized by a temporal exchange based upon memory and the image, one can look at the films made by Maya Deren, a filmmaker, dancer, choreographer, writer and photographer who was particularly active in the United States during the avant-garde period between the 1940s and 1950s. I do not offer a comprehensive critical reading of Deren's artistic production, nor do I pretend to exhaust the range of other examples that could be used to illustrate my argument. Rather, through an analysis of Maya Deren's first film, Meshes of the Afternoon (1943), I seek to show how Deren re-thinks the relationship between cinema and dance in light of a conception of dance (and, broadly speaking, of movement) as a mental activity that engages with the conundrum of the self and of the self as other in a choreography of images, memory and imagination. Paradoxical as it might seem, a conception of dance as being possible without a body can suggest the possibility of dance as a means to reactivate images, giving them back a body, freeing them from being trapped in a spectral dimension with no bodily life. This new body, however, is not entrapped in any individual corporeal identity but, rather, is multiplied across space and time. 


\section{Agamben on Dancing with 'Phantasmata'}

The philosopher and critical theorist Agamben is mostly known for his scholarly work on politics rather than on aesthetics. Agamben engages his readers with some of the most pressing contemporary concerns, from the concept of sovereignty and the rights of citizens to the concept of life itself. His method is 'paradigmatic' in so far as it uses the paradigm, which is a real case serving as an exemplum, to understand our present and its concealed grids of power and control. ${ }^{9}$ Although Agamben's oeuvre traverses disparate fields from law, to aesthetics and science, at the centre of his interest is the attempt to re-frame the present situation (status) of the refugee.

In support of 'the Agamben of poetics, culture and signification', ${ }^{10} \mathrm{I}$ argue that the question of the status of a certain subject/object is one of the chief preoccupations in Agamben's interventions in the fields of aesthetics and art, as in his reflections on politics. When it comes to aesthetics, Agamben tackles the question of status in a literal sense: how do objects (e.g., images) come to acquire the power and authority they have? How can another object/subject/event disrupt this authority? Agamben subjects to inquiry the ways in which an image (still or moving) makes meaning and the conditions under which power is to be found in each medium (cinema, video, painting, performance, dance), thus binding the aesthetic to the political.

For Agamben, man is not only a political animal as Aristotle argued, but also 'a moviegoing animal' interested in the production and consumption of images. ${ }^{11}$ The passion and intellectual interest Agamben has shown for cinema shows across his intellectual oeuvre, even if he writes only briefly about it and uses a limited range of examples. Cinema offers Agamben the opportunity to critically engage with the temporality that inhabits images - that is, their capacity to move, including from one medium to another, and thus be revitalized.

Key to grasping how Agamben sees the relationship between dance and cinema are two of his insights. First, Agamben sees cinema as being based on gestures rather than on images, and second, he thinks of dance as gesture. His understanding of cinema can be summarized by recalling his axiom 'Gesture rather than image is the cinematic element'. ${ }^{12}$ Cinema can preserve the dynamism of gesture against its becoming frozen by the image. He describes cinema 'or at least a certain sort of cinema' as 'a prolonged hesitation between image and meaning', highlighting how the two elements at the basis of cinema are not the Deleuzian movement-image and time-image but repetition and interruption, the constitutive elements of montage that restore the full potential and dynamism of the image. ${ }^{13}$ Agamben identifies cinema as a medium that dwells in a territory where potentiality reigns, rather than storytelling. ${ }^{14}$ In Agamben, gesture is 'the exhibition of a mediality: it is the process of making a means visible as such'. ${ }^{15}$ Gesture is the signifier in which human potential appears or is given form. 
Agamben's second key insight is to draw upon Aristotle's difference between praxis (action) and poiesis (production) to put forth his central thesis, which is that gesture stands separate from production or poiesis (a means to an end) and action or praxis (an end without a means), and in the process opens a new dimension of the political:

Nothing is more misleading for an understanding of gesture, therefore, than representing, on the one hand, a sphere of means as addressing a goal (for example, marching seen as a means of moving the body from point A to point B) and, on the other hand, a separate and superior sphere of gesture as a movement that has its end in itself (for example, dance seen as an aesthetic dimension). Finality without means is just as alienating as mediality that has meaning only with respect to an end. If dance is gesture, it is so, rather, because it is nothing more than the endurance and the exhibition of the media character of corporal movements. ${ }^{16}$

A gesture is a non-linguistic sign of physical presence that human beings are able to use. Dance is a gesture that settles in this void of language. Dance is gesture, however, only under specific circumstances. First, Agamben thinks of dancing not simply as a choreography of skilled and trained bodies moving in space, but as a way of enduring that enables one to deactivate movement as a means to an end. Recalling Agamben's notion of dance as gesture, Noys explains that 'what dance exhibits is not a movement that has an end, but movement for its own sake'. ${ }^{17}$ Second, through the concept of endurance, Agamben puts forth the idea that cinema makes visible that the proper medium of dance is time rather than space.

In a passage in his essay Nymphs, Agamben critically tackles the concept and practice of dance as occurring in time rather than simply space by discussing 'De arte saltandi et choreas ducendi/On the art of dancing and directing choruses', one of the most eloquent Renaissance treatises on the arts, which was written $c .1455$ by the choreographer Domenico da Piacenza (c. 1400-1476), a master of dance at the Estensi Court in Ferrara. ${ }^{18}$ Da Piacenza introduced in this treatise one of the earliest examples of dance notation in Western culture. Dance is traditionally taught through physical demonstration, and dancers, contrary to musicians, generally rely on physical memory without the help of a written score to remind them of the steps. To prevent the loss of works over time due to choreographers neglecting to preserve their routines in written form, several notation systems have been created, but none have become as popular or as standardized as music notation. To notate his choreography, da Piacenza used word descriptions rather than symbols.

The treatise puts forth the idea of dance as a medium for expressing affects, against a purely physiological-mechanistic conception of movement. To the fundamental elements of dance, such as memory, agility and measure of the ground (misura), da Piacenza adds phantasmata (images), 
arguing that whoever wants to learn the art of dancing needs to learn to dance with phantasmata, which denote

a physical quickness which is controlled by the understanding of the misura $[\ldots]$. This necessitates that at each tempo one appears to have seen Medusa's head, as the poet says, and be of stone in one instant, then, in another instant, take to flight like a falcon driven by hunger. Do this according to the prescription above, that is, using misura, memoria, maniera, misura di terreno and aire. ${ }^{19}$

The term phantasmata, Agamben argues, comes from the Aristotelian doctrine around memory.

Aristotle established a connection between time, memory and imagination by arguing that only beings who are capable of perceiving time are also able to remember, and the act of remembering requires the use of the very same faculty which we use to perceive time - that is, the imagination. It is through images (phantasmata) that human beings can not only perceive but also think. In the theory of knowledge developed in De Anima, Aristotle argued that knowledge had its origin in the senses; then it would reach the intellect through a process of abstraction operated by imagination and through the production of phantasmata. ${ }^{20}$ These images are stored in memory, which is 'an affect, a pathos of sensation or of thought'. ${ }^{21}$

The first chapter of the treatise opens with Domenico expressing his debt to the philosopher Aristotle. At the same time, Domenico laments that in Aristotle's discussions on movement in the Nicomachean Ethics, the philosopher was not able to draw forth the implications of bodily motion through space. At the beginning of chapter three, Domenico argues that

Note that aside from being blessed by God with a good mind and body, one has to learn to discern the underlying structure of this refined art form. [...] [T] he foundation is misura, which governs everything (all actions) quick or slow according to the music. Aside from this, it is necessary to have a large and deep memoria which stores all of the corporal movements (motti corporali) - natural and incidental - that are required by all performers depending upon the composition of the dances. ${ }^{22}$

Memory is not possible without phantasmata. These images, charged with memory and affect, become responsible for the movements of the body.

The phantasma is the interruption between two successive moments; it is a pause that contains the memory of the whole choreography virtually - that is the past, present and future of the dance sequence. ${ }^{23}$ Phantasmata coincide with Aby Warburg's research on the phatosformels, defined as 'an indissoluble intertwining of an emotional charge and an iconographic formula in which it is impossible to distinguish between form and content'. ${ }^{24}$ These images are 'crystals' 
imbued with time and history. With their intrinsic energy, they can move and unsettle the body of anyone who receives them and has the task of charging them with a new life.

If memory, which is one of the key elements of every choreographic sequence, is only possible in the form of an image, then to dance is to remember and to let the chain of mental images affect the body and move it forward. Dance as a practice of memory can re-activate images that, otherwise, would crystallize, becoming spectral. Corporeality, the sign of the material, passes itself off as the incorporeal. The fascination this paradox exerts reveals our discomfort with the original dichotomy between body and soul, material and spiritual. Paradoxical as it might sound, dancing would still be possible even in the absence of a moving body.

The dancer endures in her body, oscillating between the here and now (the actual movements performed within a space) and the potential of being elsewhere and else-when (the memory of what it was and the imagination of what is about to become). This quasi-cinematic chain of successive invisible images (phantasmata) not only triggers the movements of the dancer who goes forward in her choreography, but simultaneously stops the dancer for an imperceptible instant which becomes imbued with potentiality. Dancing with phantasmata, therefore, undoes the status of the body, restoring it to us transfigured, inoperative yet active, a way to deactivate the grids in which our bodies are entrapped.

Agamben clarifies the concept of inoperativity when he suggests that the "creation of a new use is possible only by deactivating an old use, rendering it inoperative" through an act of profanation. To profane something is a positive act for the simple reason that it liberates things and practices for communal usage. ${ }^{25}$ Being the manifestation of the gestural dimension proper to human beings as Agamben defines it, dance is in itself the suspension of the means-ends axis. Inoperativity does not mean the cessation of all activity, but it denotes an operation that de-activates and renders works (of art, of economy, of language, etc.) inoperative, opening them to a new possible use. Both Aristotle and Agamben maintain that anything potential is capable of not existing in actuality, and that "what is potential can both be and not be, for the same is potential both to be and not to be". Agamben finds within Aristotle a "potentiality that conserves itself and saves itself in actuality" ${ }^{26}$

To illustrate the connection between potentiality and inoperativity, Agamben uses the example of Bartleby the Scrivener. When asked by his employer to write, Bartleby, although he is fully capable of writing, replies that he would prefer not to. By becoming a scrivener who does not write, Bartleby preserves his potentiality and inoperativity, removing himself from the power structures at play. ${ }^{27}$ What happens with the potentiality of the dancer to not dance any choreographic sequences? The potential-of-not-to is maintained in the act of dancing but de- 
activated. The dancer does not stop being a dancer, even when she is not dancing, because dancing is not an activity but a form of life.

\section{Maya Deren: dancing with 'phantasmata'}

A pioneer in experimental filmmaking in the United States, Maya Deren acted as a director, cinematographer, scriptwriter, editor and performer in many of her films. Like other filmmakers such as Jean-Luc Godard and Sergei Eisenstein, Deren too was engaged in critical film theory. In her essay on Cinematography: The Creative Use of Reality (1960), she explores the intimate correspondence between the medium of film and the other arts, discussing how dance and cinema are both interested in re-staging movement. It is in her films, however, that Deren best articulates her own thinking about the relationship between cinema and dance. ${ }^{28}$ A Study in Choreography for the Camera (1945) is the first cinematic document to capture body kinetics in slow motion and space-time continuity. Here Deren explores the potential of the cinematic medium to transcend reality and the constraints of the frame. ${ }^{29}$ In the opening sequence of the film, which stars the dancer Talley Beatty, Deren's camera rotates more than 360 degrees, scanning past the dancer. One of the main features of this film is the concept of transition. The dancer raises his foot in a forest, puts it down in a museum-like space, and then returns to the forest without any continuity in space.

The only reality is that of the dancer, which exists for him alone, rather than that of the external world. The slow-motion effect allows Deren to reveal the very structure of the dancer's motion and his inner state, something that the eye cannot perceive - just as the telescope reveals the structure of matter, to use a comparison that Deren herself suggests. ${ }^{30}$ Thanks to the use of jump cuts and discontinuity editing, the camera becomes a performer, like the dancer whose body moves across different types of environment (the natural, the domestic) rather than inhabiting the very same world all the time. The body exceeds the world it inhabits; it overcomes the limits imposed by the frame, blending the cinematic with the extra-cinematic, reality and imagination, the world inhabited by the dancer in the film with the world inhabited by the onlooker. As in all her oeuvre, in A Study in Choreography for the Camera Deren is interested in exploring the relationship between time and space through the body. The spatialization of time is what she seeks to achieve by means of camera movements and discontinuity editing. In Deren's film, the camera extends the full potential of the body by having it move across the cut. By doing so, not only does Deren break down the grid of the frame, the spatial cage in which the body is entrapped, she also transforms the medium of film itself into a kind of 'muscular' body capable of enacting a change in the body on the screen. ${ }^{31}$ 
Influenced by her first-hand ritualistic experiences across different cultures, Deren's work is characterized by the attempt to achieve an organic aesthetics of the body capable of counteracting the alienation of the body brought about by modernity. ${ }^{32}$ In this respect, the ability of the camera to act as a performing body mimics what the organic body can do. This swapping between the organic and the inorganic body reminds us of the provocative paradox mentioned at the beginning of this essay: do we need an actual body to dance? To dance, to move, we need memory, we need a chain of images along which we can move without necessarily advancing in space, but rather, dwelling in layers of time: past, present and future.

The essence of dance is not movement, but chain of images imbued with time and memory, the phantasmata. As discussed earlier, Domenico da Piacenza defined dance as an act that caused an interruption (or suspension) of movement and time. This interruption, however, is charged with time - not with the present time, but with memory and potentiality. In this sense, dance does not happen when it appears to happen (now), but at an 'other' time, before or after the chronological framework within which it is performed. The gesture of the dance is a means free of purpose, pure mediality suspended between memory (past), event (present), and potential (future).

Dancing with phantasmata first emerges in Meshes of the Afternoon (1943), her first experimental film, made in collaboration with the filmmaker Alexander Hammid. Although strictly speaking this film does not present any actual dancing directly, Deren uses a series of formal cinematic innovations to explore, through a moving body, a variety of themes that will remain central throughout her artistic production, such as the relationship between movement and stasis, the constraints posed by the physical body, the porous membrane between interiority and the surface of the visible, and the fragmentation of subjectivity. Meshes of the Afternoon, which has been defined by Fabe as a psychotopography imbued with Freudian motives and symbolism, is organized around a basic movement performed by a young woman (Deren) and her other doubles. ${ }^{33}$

A first young woman walks along a road, picks up a flower, and glimpses the back of another figure disappearing around a bend in the road ahead of her. After knocking, the young woman tries the locked door of a house, takes out a key, drops it, and pursues it as the key bounces in slow motion down a staircase. She then climbs the stairs, passes a telephone with the receiver off the hook; a shot of her eye and one of a window are intercut until they are both clouded over. Inside the house, the camera moves subjectively, adopting the point of view of the young woman. This initial movement is repeated, each time with subtle variation. There is a fluid transition from the first-person point of view to the third. As the film proceeds, under the influence of cinema pioneer Méliès and his editing style, Deren plays cinematic tricks: the key comes out from the woman's mouth and turns into a knife in her hand. The woman enters a room through the unlocked door. 
Inside, there are now two female figures seated at the table. The newcomer joins them and places the key on the table. One of the female figures, wearing goggles, stands up and holds the knife aggressively.

Instead of recording actual events, the film is concerned with the interior landscape of what the female protagonist experiences, fears or dreams of while she moves across different spaces. It explores how the sub-conscious of a woman elaborates an apparently simple and casual incident into a critical emotional experience. The play of repetition, circularity and variation accompanies the protagonist as she walks across different spaces, the soil, the grass, the beach and the concrete. There is no logical narrative trajectory, but a dream-like movement (a dance) which progressively draws the spectator in and brings her back. The theme of the double becomes visible thanks to a series of formal choices, from the motif of reflection in the mirror, to the circular, dream-like and repetitive structure of the film.

In Deren's films, all made with amateur means, bodies move at great speed, take back actions, slide on the ground without touching it, disrupt the laws of physics, and by doing so, they challenge any assumption of dancing as a mere physical activity concerned with virtuosic bodies moving in space. By engaging with dance as a mental rather than physical activity similar to a state of trance, Deren attempts to liberate dance from the constraints of the body by means of the cinematic medium. In this respect, Meshes of the Afternoon shows how Deren is concerned with dance even in the absence of a dancer or choreography. The main protagonist of the film is movement - of a female body, inanimate objects and the psyche. Movement as the cipher of being alive is a recurring motif in Renaissance paintings such as La Nascita di Venere (Birth of Venus) by Botticelli (1482-1485), in which the painter masterfully coped with the challenge of representing movement on a necessarily static canvas. The dialectics between movement and stillness, between dance and the image, is addressed by da Piacenza using two symbols: on the one hand, Medusa's head signifying petrification, stoppage - interruption, to use Agamben's word; on the other, the flight of the falcon to signify movement and action. With its sudden freezing of movement, the concept of phantasmata itself is linked to the myth of Medusa, who can turn people into stone by looking at them.

The myth of Medusa has traversed all Deren's filmic productions: Medusa (1949) is the title of an unfinished work that she made at the YMHA film workshop with the dancer Jean Edrman, whose performance on the transformations of Medusa were to serve as the basis for Deren's film. ${ }^{34}$ The myth becomes metaphorically visible in Meshes of the Afternoon. In the so-called "Botticelli" medium shot, Deren herself is portrayed inside the domestic space with her hands pressing against a glass wall - a membrane between herself and the world outside. ${ }^{35}$ Deren looks at a series of moving 
images that are the doubles of herself. She is framed standing still, observing the spectacle of her two other selves, one of whom races to chase the hooded figure walking in front of her. Tree branches reflected on the glass window seem to grow from Deren's Medusa-like head, anticipating the seaweed that signals the sleeper's death. ${ }^{36}$ The hooded figure with a mirror instead of a face appears in the film before Deren's own face, which has been withheld up to this moment. It is only through the mirror and the spectacle of the other selves that we witness the sudden unveiling of Deren's face. The Medusa myth resonates here. The frontal stillness that characterizes Medusa's terrifying image is dangerous - one cannot look into Medusa's eyes without being turned to stone and, therefore, access to Deren's face is given only through a play of reflections and doubles in constant movement. What is watched directly can kill, but if viewed as a reflection, by indirect vision as in the myth of Perseus, it does no harm.

Etymologically, the word spectrum means image, apparition, spectre. This is where Deren's work and da Piacenza's concept of dancing with phantasmata come together. During their (both collective and individual) transmission, images tend to ossify in spectral presences. The task is then to bring these images back to life as cinema can do. The spiral constituted by cinema and dance in Deren becomes a symptom of an underground current that returns to the surface, bringing back ghost-like images, the debris of half-forgotten memories and sensations. Things seem as if they were subject to a gradual fading out, but not in the sense of disappearance. Very much like history, onscreen images themselves are characterized by returns and repetitions. For example, the laying out of the lily at the beginning of the film is the visual and material anticipation of the deposition of Deren's own dead body that closes the film.

Similarly, elements of the mise-en-scène that Deren uses in her everyday household activities, such as the knife, the key and the telephone, are all ghost-like traces of repressed memories, recurring motifs reflecting the hidden chaos that characterizes all the spaces in which the action of the doubles takes place. Deren's body fails to master this fragmented space of the psyche: “Deren's doubles are imaginary, but they produce 'real' effects. In this way, 'otherness' is a mythic and abstract force beyond individual control - as is movement - yet it is not located in the external environment alone." ${ }^{, 37}$ This is the dance of the film itself. As the film proceeds, all the scattered images of the self come back together into a configuration that points to the end of movement (the end of life, if movement is a sign of life), which coincides with the return of the physical body, still, immobile, at the end of the film - Deren's own dead body. Physical reality, like the physical body, is subjugated to the logic of the protagonist's psychic world of memories and fantasies, ultimately causing her death. In this film, Deren's movement and the almost imperceptible movements of the objects forming the mise-en-scène are mental rather than just physical; they are "mini- 
choreographies at the body's periphery". ${ }^{38}$ Deren's choreography of mental images and mnemic traces, therefore, can get her out of her own physical body and its constraints.

Dance in film lays bare the medium of cinema in all its potential. This article has shown how Agamben's understanding of dance can give us a framework through which the relationship between dance and cinema can be re-assessed. Dance is more than a highly-skilled sequence of movements that require trained bodies in order to be performed; in dance, the body endures its own mediality. As Maya Deren's first film Meshes of the Afternoon shows, the true place of the dancer is not her body, nor the movement performed, but the chain of images (phantasmata) that function as a Medusa's head, as an interruption, albeit not petrifying but liberating, an interruption charged with dynamism and potentiality.

Ultimately, dance as gesture undoes the existing economy of bodily movements. It undoes the status of the body, restoring it to us transfigured, inoperative yet active, a sign of resistance against the grids in which our bodies are trapped, the spatial-temporal grids of the here and now. Dance is not the liberated impulse: it is disobedience to an impulse. Agamben's concept of potentiality resonates here. Dance as gesture reveals a human action as a means without ends, as a form-of-life. Agamben defines the art of living as 'the capacity to keep ourselves in harmonious relationship with that which escapes us' ${ }^{39}$ The art of dancing, one could conclude, is a form of life constituted by a radical openness, which becomes visible when we dare to dance with images and relics of memory - phantasmata.

King's College

University of Aberdeen

Aberdeen AB24 3FX

United Kingdom

silvia.casini@abdn.ac.uk

\section{NOTES}

\footnotetext{
${ }^{1}$ Space and Being in Contemporary French Cinema, ed. by James S. Williams (Manchester and New York: Manchester University Press, 2013), p. 2.

${ }^{2}$ Marta Braun, Picturing Time: The Work of Etienne-Jules Marey (1830-1904) (Chicago: University of Chicago Press, 1995). Eadweard Muybridge, The Human Figure in Motion (London: Dover, 1955).

${ }^{3}$ Erin Brannigan, Dancefilm: Choreography and the Moving Image (New York: Oxford University Press, 2011), p. 7. Another comprehensive and rigorous exploration of dance and media is Sherril Dodds, Dance on Screen: Genres and Media from Hollywood to Experimental Art (Basingstoke: Palgrave, 2001). Both studies provide readers with an overview of the genre of dance films, using a variety of critical approaches and
} 
theorists as well as offering a close reading of selected dance films. Brannigan focuses, in particular, on the legacy of Maya Deren. Dodds traverses a wide range of genres focusing on the relationship between dance, spectators and the camera.

${ }^{4}$ See Laurance Louppe, Poétique de la danse contemporaine (Brussels: Contredanse, 2004).

${ }^{5}$ See, for example, the reflections on dance and the body by Nietzsche, Rilke, Valéry and Merleau-Ponty, among others. See Friedrich Nietzsche, The Birth of Tragedy and Other Writings, ed. Raymond Geuss and Ronald Speirs (Cambridge University Press, 1999) and Thus Spoke Zarathustra: A Book for All and None, ed. Adrian Del Caro and Robert Pippin (Cambridge University Press, 2006). Rainer Maria Rilke, Dance the Orange: Selected Poems, trans. by Michael Hamburger and edited by Jeremy Mark Robinson (Crescent Moon, 2008); Paul Valéry, Dance and the Soul (Lehmann, 1951); Maurice Merleau-Ponty, M. (1969) The Visible and the Invisible (Northwestern University Press, 1969) and The Phenomenology of Perception Routledge, 2002).

${ }^{6}$ Alain Badiou, Handbook of Inaesthetics, trans. by Alberto Toscano (Stanford: Stanford University Press, 2005), pp. 57-58. Nietzsche relies on the concept of dance in the characterization of all his major thoughts. It is integral to the economy of the Dionysian and the Apollonian, and to the theory of the will to power.

${ }^{7}$ See Benjamin Noys's seminal essay on Agamben: Benjamin Noys, 'Gestural Cinema?: Giorgio Agamben on Film', Film-Philosophy, 8.22 (2004). < http://www.film-philosophy.com/vol8-2004/n22noys> (Accessed: 10 July 2017). To further explore the relationship between Agamben and cinema, see Janet Harbord, Excentric Cinema: Giorgio Agamben and Film Archaeology (New York and London: Bloomsbury, 2016). ${ }^{8}$ Jonathan Owen Clark, 'Dance and Subtraction: Notes on Alain Badiou's Inaesthetics', Dance Research Journal, 43.2 (2011), 51-64 (p. 60).

${ }^{9}$ On Agamben's paradigmatic method, see Giorgio Agamben, The Signature of All Things. On Method (Cambridge, MA and London: Zone Books, 2009), and Leland De La Durantaye, Giorgio Agamben. A Critical Introduction (Stanford: Stanford University Press, 2009), pp. 200-43.

${ }^{10}$ Christian McCrea, 'Giorgio Agamben', in Film, Theory, and Philosophy: The Key Thinkers, ed. by Felicity Colman (Montreal: McGill University Press, 2009) p. 350.

${ }^{11}$ Giorgio Agamben, 'Difference and Repetition: On Guy Debord's Films', in Guy Debord and the Situationist International, ed. by Tom McDonough (Cambridge, MA: MIT Press, 2002), pp. 313-19 (p. $314)$.

${ }^{12}$ Giorgio Agamben, 'Notes on Gesture' in Infancy and History: On the Destruction of Experience, trans. by Liz Heron (New York: Verso, 1993), p. 136. This text, which has appeared in English in three different versions, was first published by Agamben in 1991 under the title 'Notes sur le geste' in the cinema journal Revue Trafic, founded in the same year by film critic Serge Daney.

${ }^{13}$ Agamben, 'Difference and Repetition', p. 317.

${ }^{14}$ As I have discussed elsewhere, the concept of potentiality occupies a central position across all Agamben's oeuvre. See Silvia Casini, 'Engaging Hand to Hand with the Moving Image: Grandrieux, Serra and Viola's 
Radical Gestures', in Cinema and Agamben. Ethics, Biopolitics and the Moving Image, ed. by Henrik Gustafsson and Asbjørn Grønstad (New York and London: Bloomsbury, 2014), pp. 143-69.

${ }^{15}$ Agamben, 'Notes on Gesture', in Means Without End: Notes on Politics, trans. by Vincenzo Binetti and Cesare Casarino (Minneapolis: University of Minnesota Press, 2000), p. 58.

${ }^{16}$ Ibid., p. 58.

${ }^{17}$ Benjamin Noys, 'Gestural Cinema?' < http://www.film-philosophy.com/vol8-2004/n22noys> (Accessed: 10 July 2017).

${ }^{18}$ Giorgio Agamben, 'Nymphs', in Releasing the Image: From Literature to New Media, ed. by Jacques Khalip and Robert Mitchell (Stanford: Stanford University Press, 2011), pp. 60-80.

${ }^{19}$ A. William Smith (translated and annotated by), Fifteenth-Century Dance and Music. Twelve Transcribed Italian Treatises and Collection in the Tradition of Domenico da Piacenza, Volume 1: Treatises and Music. Volume II: Choreographic Descriptions with Concordances of Variants (New York: Pendragon Press, 1995), Vol. 1: p. 13.

${ }^{20}$ Aristotle, On the Soul (De Anima), in The Basic Works of Aristotle, ed. by Richard McKeon (New York: Random House, 1966), 595 (432a).

${ }^{21}$ Agamben, 'Nymphs', p. 63. On the Aristotelian theory of memory, see Aristotle, On the Soul (De Anima), p. 595 (432a).

${ }^{22}$ Smith, 1995, p. 13.

${ }^{23}$ Agamben, 'Nymphs', p. 62.

${ }^{24}$ Giorgio Agamben, 'Aby Warburg and the Nameless Science', in Potentialities: Collected Essays in Philosophy, trans. and ed. by Daniel Heller-Roazen (Stanford: Stanford University Press, 1999), p. 90.

${ }^{25}$ Giorgio Agamben, Profanations (Boston: Zone Books, 2007), pp. 85-86.

${ }^{26}$ Agamben, 'Aby Warburg', p. 184. See Aristotle, Metaphysics (Cambridge, MA: Harvard University Press, 1986).

${ }^{27}$ Agamben, 'Bartleby, or On Contingency', in Potentialities: Collected Essays in Philosophy, pp. 243-274. ${ }^{28}$ The film Ritual in Transfigured Time (1946) confirmed Deren's interest in the theme of rituality, while in Meditation on Violence (1948), the director's focus is on the performer Chao Li Chi. One of Deren's last works, The Very Eye of Night (1958), shot in collaboration with the Metropolitan Opera Ballet School, is now regarded as an avant-garde intuition of contemporary digital dance: here the dancers, like white ghosts, sway in the scenic notion of a virtual night and starry space.

${ }^{29}$ For an examination of Deren's film as the transformation of dance into avant-garde film, see Amy Greenfield, 'The Kinesthetics of Avant-Garde Dance Film: Deren and Harris', in Envisioning Dance on Film and Video, ed. by Judy Mitoma (New York and London: Routledge, 2002), pp. 21-26.

${ }^{30}$ Maya Deren, 'Cinematography: The Creative Use of Reality', Daedalus, 89.1 (1960), 150-67.

${ }^{31}$ Andrew Nell, 'The Medium is a Muscle. Abstraction in Early Film, Dance, Painting', in Film, Art, New Media: Museum Without Walls?, ed. by Angela Dalle Vacche (London and New York: Palgrave, 2012), p. 59. 
32 Alison Butler, "'Motor-Driven Metaphysics”: Movement, Time and Action in the Films of Maya Deren', Screen, 48.1 (2007), 1-23. See also Satin Leslie, 'Movement and the Body in Maya Deren's Meshes of the Afternoon', Women and Performance: A Journal of Feminist Theory, 6.2 (1993), 41-56.

${ }^{33}$ Marilyn Fabe, 'Maya Deren's Fatal Attraction: A Psychoanalytic Reading of Meshes of the Afternoon, with a Psycho-Biographical Afterword', Women's Studies, 25 (1996), 237-54.

${ }^{34}$ See Sarah Keller, Maya Deren: Incomplete Control (New York: Columbia University Press, 2014), p. 222. Maya Deren often refers to mythology and divinity: in Ritual in Transfigured Time she takes inspiration from Dionysian movements and Hellenic statues; Study in Choreography for Camera (1945) starts at the statue of a Buddha; and The very eye of night (1958) stages translucent dancers floating between constellations and archaic symbols. Some aspects of the Medusa myth can be related to Maya Deren's filmic work. See Keller, Maya Deren, passim.

${ }^{35}$ For a close reading of this shot, see Maria Pramaggiore, 'Seeing Double(s): Reading Deren Bisexually', in Maya Deren and the American Avant-Garde, ed. by Bill Nichols (Los Angeles and London: University of California Press, 2001), pp. 237-60.

${ }^{36}$ Becky Paterson, 'Fabric in Film and Film as Fabric: Maya Deren's Meshes of the Afternoon', Textile, 8.2 (2010), $228-43$ (p. 240).

${ }^{37}$ Pramaggiore, 'Seeing Double(s)', p. 239.

${ }^{38}$ Brannigan, Dancefilm, p. 1.

${ }^{39}$ Giorgio Agamben, Nudities (Stanford: Stanford University Press, 2010), p. 114. 